\title{
What About Me? Theorizing Power and Pushback in Advancing Marginalized Identities
}

\author{
Sara Schley ${ }^{1 *}$, Deborah L. Blizzard ${ }^{1}$, Annemarie Ross ${ }^{1}$, Carol E. Marchetti ${ }^{1}$, Wendy A. Dannels ${ }^{1}$, \\ Karen J. Beiter ${ }^{1}$, Denise S. Kavin ${ }^{1}$, Susan B. Foster ${ }^{1}$
}

${ }^{1}$ Rochester Institute of Technology, Rochester, USA

*Corresponding Author: sxsdor@rit.edu

Citation: Schley, S., Blizzard, D. L., Ross, A., Marchetti, C. E., Dannels, W. A., Beiter, K. J., Kavin, D. S. and Foster, S. B. (2019). What About Me? Theorizing Power and Pushback in Advancing Marginalized Identities, Journal of Cultural Analysis and Social Change, 4(1), 01. https://doi.org/10.20897/jcasc/5844

Published: July 19, 2019

\begin{abstract}
In 2012, the Rochester Institute of Technology (RIT) received an NSF ADVANCE Institutional Transformation grant to improve the career advancement of women. The National Technical Institute for the Deaf, one of RIT's colleges, had over 30 Deaf and Hard of Hearing (DHH) female faculty members. The project designated a DHH female faculty team with a budget to conduct a self-directed program of development and networking: the DHH Women's Connectivity Series. Starting in 2014, other faculty began to request access to these sessions - hearing male and female faculty, DHH male faculty, and faculty of color. They argued that they too experienced marginalization due to issues of gender, race, ethnicity and hearing loss. This article summarizes the Connectivity Series' story of power, privilege, and pushback. How do DHH women successfully negotiate careers in academia, given the impact of intersectional minority identities (disability, gender, etc.)?
\end{abstract}

Keywords: power, pushback, marginalized identities, faculty, disabilities

\section{INTRODUCTION}

Playgrounds make great ethnography, and so do academic institutions. At a minimum, both create complex case studies from which critical scholars can observe power hierarchies in motion. While both contexts seem disparate, self-expression is evident at each. Twentieth century French social theorist Michel Foucault reminds us that, under the sanitized view of children playing and scholars working, other invisible forces are at play and work. There is an implied hierarchy in which the mainstream majority, 'Us', seeks to maintain power and privilege (advantages in society for being members of certain groups, or, background qualities which don't get in the way of navigating trhough your world) by calling attention to the perceived weaknesses of another group, the 'Other' (Foucault, 1977).

In 2012 the Rochester Institute of Technology (RIT) was awarded a five-year grant from the National Science Foundation's ADVANCE program. The primary mission of ADVANCE is to increase the participation and advancement of women in science, technology, engineering and mathematics (STEM) careers in academia through institutional transformation. A secondary mission is to conduct social science research that examines one or more areas relevant to the project's over-arching mission. The National Technical Institute for the Deaf (NTID), one of 
the nine colleges at RIT ${ }^{1}$, had over 30 Deaf or Hard of Hearing (DHH) women faculty members. As an underrepresented group within the target population of ADVANCE, DHH women were identified as a primary focus of study. The project sought to document the experiences of DHH women in higher education and identify potential strategic interventions, opportunities, and resources that may mitigate barriers encountered en route to careers in academia. A team of DHH women faculty was provided a budget to conduct social science research, and a self-directed program of professional networking and development called the DHH Women's Connectivity Series. After a year of offering these sessions, other NTID faculty began to request access to them - hearing men and women faculty, DHH men faculty, and faculty of color. They argued that they too experienced marginalization due to issues of gender, race, ethnicity and hearing loss and that limiting the sessions to DHH women created a divide among faculty and denied other faculty the opportunity to benefit from this series. In summarizing the story of the DHH Women's Connectivity Series, we discuss issues of power, privilege, and pushback that complicate efforts to advance equity for those with disabilities (and perhaps those with a different form of otherness: gender, race, ethnicity, etc.) in STEM fields.

This reflective article examines a phenomenon we term power-push by which individuals from a disempowered group attempt to push themselves metaphorically, and at times physically, into a more powerful stance within a given multicultural context (e.g., attempts at gaining access to workshops limited to DHH women). To better understand how and why these power-pushes occurred, we examine the DHH women faculty team's reflection on their work environment and subsequent implementation of the DHH Women's Connectivity Series. From a social justice perspective, this programming was a reasonable course of action; however, many of those involved in delivering the DHH Women's Connectivity Series encountered a negative pusbback from individuals who who did not fall into the target population for this programmatic attention. These persons pushed against the Other for what they perceived to be inequitable access to special resources and opportunities that could enhance their own professional position. While some of these were different kinds of Other (e.g., DHH men, faculty of color), some were mainstream majority faculty (white male and female). This article outines a question that emerged as we observed this pushback: How did these DHH women successfully negotiate careers in academia, given the impact of intersectional minority identities (disability, gender, etc.)?

\section{REVIEW OF LITERATURE}

Intersectionality. Intersectionality considers the effect of a multiple of discriminations and disadvantages on a person or on groups (Crenshaw, 1989). The 'Double Jeopardy' hypothesis suggests that a minority woman's membership in an additional minority group increases her disadvantage (King, 1988). Certainly, the complex social structures do not operate using a principle of additivity, however, the reality remains that minority women's experiences are unique, comparable neither to those of white women nor to those of men of the same ethnicity. Coston and Kimmel (2012) looked at samples of white men who were also either disabled, gay, or working class: in other words, they were privileged in one sphere and unprivileged in another. Gay, working class, or disabled men are thus as "less male" given their marginalizations. These men used different strategies in managing questions of their masculinity based on their class, sexuality, or bodily status.

Diversity in Academia. A number of scholars have focused on the challenges faced by underrepresented racial and ethnic minorities within academia (e.g., Turner, Haddix, Gort, and Bauer, 2017). Numerous factors influence successful negotiation of tenure, such as multiple written and unwritten standards of advancing through the academy (e.g., Matthew, 2016; Rockquemore and Laszloffy, 2008), increased demands of mentoring and service (e.g., Rockquemore and Laszloffy, 2008; Turner, Walker-Dalhouse, and McMillon, 2005), and overrepresentation of numbers on contingent vs. non-contingent tracks (Finkelstein, Conley, and Schuster, 2016). Similarly, for decades, feminist scholars have examined the inequities facing women academics within the academy, a historically hegemonic, masculine, institution. There are similar issues of representation (Finkelstein, Conley, and Schuster, 2016), biases against caregiving responsibilities (e.g., Drago et al., 2005), hesitation to use family leave policies (see Williams, 2004), additional emotional labor as a female faculty member (El-Alayli, Hansen-Brown and Ceynar, 2018), and increased service loads (Guarino and Borden, 2017).

Often romanticized (by outsiders) as inherently equitable due to its emphasis on objectivism and scientism, academia is assumed to be a hallmark of meritocracy (see Dench, 2006). The scholar rises and falls in direct relationship to demonstrations of their ability (on objectivism and scientism, e.g. Blizzard, 2007). However, when

\footnotetext{
${ }^{1}$ At the time of the events in this study, there were 9 colleges at RIT: College of Applied Science and Technology, Saunders College of Business, College of Science, College of Imaging Arts and Sciences, College of Liberal Arts, Kate Gleason College of Engineering, Golisano College of Computing and Information Sciences, College of Health Sciences and Technology, and the National Technical Institue for the Deaf. Since then, some of the colleges have changed names, and there are a few new degree granting units. For more details, see https://www.rit.edu/colleges.
} 
examined under a critical frame of gender, power, and race, this narrative quickly dissipates into little more than a cultural myth, ensuring the further entrenchment of inequity disguised in objectivism. In this light, power can be seen as concentric circles in which the 'norm' (and the power, the objective) of scientific ideal resides in the epicenter (e.g., white, male, hearing, straight), with Others maintaining cultural space further out from the center. Thus when examining individuals with less cultural capital, it is noticeable that they live and work in the outer reaches of these circles: where difference in gender, race, and body politics (including physical, social, and mental differences, among others) are often seen as threatening to the already accepted and entrenched status quo. A crucial question emerges: what happens when one group pushes into the power of the privileged?

Feminist Critiques of Inequities. Many feminists in Science and Technology Studies (among other areas of thought) have examined the processes by which women categorized through either sex or gender, terms that are themselves socially created and scientifically categorized, are often structurally and systematically pushed out of science due to overt and subversive behaviors within the field (e.g., Fox Keller 1995; Harding 1986; Wyer et al., 2009). One approach, offered by Mary Babercheck, to viewing how and why women are repressed in STEM disciplines focuses on either differential treatment (a deficit model) or on innate differences in how men and women act and behave (a difference model). In her analysis of social behaviors of men and women in STEM education she writes that the deficit arguments support the belief that women are comparably at a loss, or deficit, in how much STEM education they may receive (e.g., some studies to support this approach include accounts of girls not being called upon in STEM classes or being silenced or spoken over by male classmates). The second approach, the difference model, lies more in line with arguments of biological determinism: put simply, girls are not 'wired' to excel in the STEM disciplines. Although biological determinism is often countered by theories of social constructivism, its cultural pervasiveness remains strong. These explanations are not new and are rooted in biology. For example, in the 1800s, theologians, biologists, and social scientists believed that if women were educated, blood would flow away from their most precious organs and be redirected to the brain; this would in turn cause severe social disruption. In 1873, Edward H. Clarke, Professor of Education at Harvard University, argued that girls should be spared higher education or they would fail to reproduce ... instead the immigrants would reproduce thus outnumbering the 'whites' (Clarke, 1873; Zschoche, 1989). Alongside sexism, racism was at play.

Ultimately, Barbercheck (2009) argues that neither the deficit nor the difference model '... adequately takes into account the force of stereotypes, gender schemas, and images that surround us but do not seem to have the direct or concrete power to shape an individual's choices' (p.119). She points out that while stereotypes may or may not be true, that is not enough reason to disregard them. She writes, '... scientists are often not aware of the biases that may arise from the stereotypes of men and women. A prevailing assumption is that gender is irrelevant in doing science, and therefore is irrelevant in the culture of science (see also, Fox Keller, 1995). But if gender is truly irrelevant, then one would expect that the images of people in professional publications would be quite different from those in broader culture,' since the broader culture contains enormously gendered and sterotyped images (p. 119). Her findings suggest that this is not the case. In a study of diversity in science advertisements, the images are predominantly men and white. So diversity as a concept is gendered: it is women (Zuska, 2007).

Mackinnon (1987) focuses instead on gender dominance. Difference is that while (say) men and women have differences, underlying these differences is a sameness - that of humanity. Dominance, instead, acknowledges that while men and women may both be human, there is an unstated measurement of maleness that is "more than;" there is a hierarchy, and men and male are at the top. This higher status is moreover unstated, and inherently better than the lower status: it is an unacknowledged privileged status. McIntosh (1989) extends this from gender to race, and clarifies how privilege carries with it an "invisible knapsack" of qualities which allow freedom of confidence, criticism, comfort, and control of decisions - where those without the privilege suffer negative consequences for the same decisions. Thus, this privilege is really about conferring dominance because of one's race or sex. Difference is therefore inferior - the dominant group is so because it is superior. For some, the push for equality can feel like oppression. Since many of those in positions of privilege do not easily see their privilege, and since the lack of privilege is by definition "less than" or inferior, it is easy to feel that those who want equality want those in privilege to give up at least some of their power. In addition to the general invisibilty of the position of privilege, because there is diversity in dominant ways of being, there is space for marginalization - and with it - inferiority (Cheng, 2008).

Disability and DeafStudies. It is not a stretch to overlap disability identity with these gender and race analyses of privilege. Since the 1970s, disability studies has focused on social, cultural and political contexts of disability, and has recognized that - like gender, ethnicity, and race - disability is a key aspect of human experience, and disability has important implications for political, social and economic arenas of society (Shuttleworth and Meekosha, 2017). Garland-Thomson (2017) and Thomson (2017) argue that when scholars of disability studies tackle new areas and problems within their discipline, they often replicate what has previously been done within feminist studies: many issues overlap, and in the end are part of a larger arena of identity studies. Certainly deaf studies can fit under this analysis too. 
Models of deafness include the medical model and the sociocultural model (see Higgins and Lieberman, 2016). Legally and educationally, DHH individuals are served under the Individuals with Disabilities Education Act (Individuals with Disabilities Education Act, 1997) and the Americans with Disabilities Act (Public Law, 1990). These laws entitle services and accommodations (e.g., ASL/English interpreters, speech-to-text captioning, etc.). This is a medical model of disability: The disability is treated as something to ameliorate and accommodate within a world built for those without special needs. The medical model is focused on the absence of hearing ability. Deafness is a condition that requires some form of remediation (Woodward and Allen, 1993). By contrast, in the sociocultural model of deafness, the deaf person's interactions with individuals and institutions in their culture shape who they are (Power, 2005). Given specific environmental contexts, the dis- part of the disability disappears. Here, deafness is a culture, with its own language, etiquette, accepted behaviors and humor. Deaf individuals are a cultural and linguistic minority, where access to language is framed as a human rights issue (Grojean, 2001; Siegel, 2008). While access to spoken language via interpreters (for example) is still necessary, it is necessary because of the multilingual context (spoken English, ASL) of individuals interacting, not because the deaf indivduals are "not hearing" and deficient.

It is worth nothing that there are a number of ways where Deaf Studies and Disability Studies diverge as fields rather than intersect (see Burch and Kafer, 2010). The biggest reason for this is the importance of language as a focus: where being Deaf is centered as a cultural difference. However disability and deaf students staunchly overlap in their focus on identity, on lack of patholization, and emphasis on a social rather than medical model.

The field of disability studies has also examined "ability privilege," i.e., unearned benefits that accompany being typically abled individuals (Bialka and Morro, 2017), extending the critical race and gender conversations to ability status. Like gender and race discussed above, those who are able are typically unaware of their privilege, although they may have a level of pity or concern about the deficits of those with disabilities (c.f., the medical model). Confronting ableism (Hehir, 2005; Hehir \& Katzman, 2012; Wolbring, 2008; Valle and Connor, 2011) thus similarly focusses on a dominance model of ability/disability, rather than deficit or difference models (c.f. discussion on these models above).

Academics with Disabilities. Not surprisingly, academics with disabilities experience challenges of dominance and privilege. Inckle (2018) discussed the prevalence and extent of her experience with unpaid labor done in order to get her own physical accessibility needs met. Negotiating for accessible teaching spaces, parking spaces, and bathrooms, adds extensive hours and emotional work to her daily work life. Brown and Leigh (2018) discuss issues of when and whether to disclose disability status (and the inherent risk/benefit decisions), and challenges of accessing basic arenas of academic networking like conferences. Disabled faculty may feel pressured to behave as "non disabled" as possible - being disabled is a weakness, one that adds to the already difficult tenure and promotion processes. The contradiction between the mental image people hold of an academic (highly qualified, bright, capable) and an "abnormal body" disrupts normative assumptions about who is qualified to be a faculty member and how they should act and behave (Iantaffi, 1996). Faculty with disabilities may also internalize shame and stigma from societal attitudes, which may reduce their willingness to seek necessary accommodations (Evans, Broido, Brown, Wilke, and Herriott, 2017).

Kerschbaum et al. (2017) present a volume on negotiating disability, disclosure, and diversity in higher education. Multiple chapters present the complexity of the issue, and argue for inclusion of disability in the intersectionality picture alongside diversity, gender, race, and sexuality. Authors take the view that "diversityincluding disability—is broad, complex, multileveled, intersectional, and dynamic" (p. 3). While diversity often does not include disability within the discussion, this books argues that it should be included. Further, disability identities "intersect with, emerge with, and are influenced by myriad aspects of embodied presence and experience" (p. 6). As such, disclosure of disability is a fluid and evolving process, dependent on multiple contextual factors.

Dolmage (2017) offers a thorough analysis of "academic ableism." Using three metaphors of "access" to higher education, Dolmage cogently lays out layers of challenges for those with disabilities accessing and succeeding at higher education. The first metaphor considers "steep steps:" literally and figuratively, if those with disabilities can conquer challenging access issues (physical and otherwise) and succeed despite these challenges, they are afforded access to the academy. The second metaphor, "retrofitting," considers present-day US law and entitlements - such that the ADA guarantees "access" in the form of adding structures and supports that allow for access to challenging settings and scenarios. The ramp gives access to entrances with stairs...but it is a retrofit, that works sometimes better than other times (e.g., ramps are at times behind buildings with inconvenient entrances). Here the focus is on compliance with the law, not designing spaces for access by those with diverse abilities and physical attributes. The third metaphor, one of "universal design," focusses on designing inclusive spaces from the get-go (see also D’Souza, 2004; Mace, 1985; Meyer, Rose, and Gordon, 2014).

Dolmage (2017) further delineates a long history of able-bodied people perceiving disabled people getting accommmodations and services as "gaining advantage." Stigma surrounding disabilities is pervasive: "This begins with the idea that the university is the space for society's most able, physically, mentally, and otherwise—not a 
place to admit to any weakness or challenge. There is also the quite reasonable feeling that you will be accused of faking it, even though the financial cost and labor involved in faking a disability would vastly outweigh any benefits. And the benefits are negligible-note-taking and extra time or space for tests or exams can help, but the accommodations model too often assumes that learning only happens in lectures and high-stakes tests, and hasn't kept up with the modern classroom." (p. 96).

Intersectionality - gender and disability. Williams, Phillips, and Hall (2014) based on interview and surveys of women in STEM, reported that both women of color and white women experience pervasive gender bias, but in different ways. Clancy et al. (2017) surveyed 474 astronomers and planetary scientists between 2011 and 2015 about their workplace experiences, and found overwhelmingly that women of color experienced higher rates of negative workplace experiences than white women or men of color. Weisel and Cinamon (2005) asked 74 DHH and 91 hearing high school students to rate the suitability of 25 occupations (varying according to prestige and required level of communication) for deaf men and women. The findings showed that occupations requiring intensive communication were considered less suitable for deaf individuals than those requiring less communication. Among DHH adolescents, highly prestigious occupations were not considered suitable for deaf adults even when communication barriers were irrelevant. The evaluations of both DHH and hearing participants showed a negative bias toward deaf women's competence.

Woodcock et al. (2007) describe the barriers that Deaf academics face, including the problem of convincing potential colleagues that they can do the job, as well as the hearing community's lack of knowledge about deafness. Once a Deaf academic has been awarded tenure, he or she may not feel encouraged to seek promotion. Career success can be linked to strong networking and collegiality, but Deaf people are denied access to both internal and external networks. Punch (2016) reviews studies that provide evidence that DHH employees experience greater levels of fatigue, psychophysiological stress, and stress-related sick leave than their counterparts with no hearing loss experience.

\section{CONTEXT: THE DHH WOMEN'S CONNECTIVITY EXPERIENCE OF AT RIT/NTID}

NTID has a sizeable number of DHH faculty. This presented a unique opportunity to study faculty with an identified disability, working within a context of multiple supports for DHH students and faculty. The $D H H$ Women's Connectivity Series launched during the 2013-2014 academic year, in which six events were held for DHH women faculty only. The first was a planning session where participants suggested future topics such as grant writing, career advancement, and self-advocacy. Subsequent sessions included DHH faculty who shared their individual pathways to academic posts, researchers who discussed strategies for writing proposals for external funding, discussion of challenges and strategies for networking at largely hearing conferences, and other areas of interest. Guests included local, regional, national and international visitors. Since the population of DHH women academics is relatively small and geographically diverse, online and video conferencing allowed for interaction with national and international colleagues. It soon became evident, however, as scholars of the institutionalization of power have noted, that pursuing fundamental change and unsettling the status quo led our team members to unearth a collective pusbback to these events for DHH women.

As the DHH Women's Connectivity Series continued, it became clear that many people with a variety of differences marking them as Other found themselves on a perceived losing end of potential advantages. These benefits were reserved for individuals who identified within the labels of marginalization: series advertisements and announcements of events invited 'Deaf and Hard of Hearing Women Faculty.' Being a DHH man did not qualify them, nor did being a hearing woman or man of color, nor did a DHH man of color, nor a staff person; you had to identify as a women, as a faculty member, and as DHH. ${ }^{2}$ Being in double, triple, or quadruple jeopardy was not enough. The marginalization needed to be of a specific type; the jeopardy had to be in a particular category. As we now look at our findings the question emerges: Was this the correct decision? The answer is as simple as it is complex: yes and no.

The excitement of better understanding the context of DHH women faculty, however, was quickly questioned by Others outside this marginalized group who felt equally or similarly maligned. Why, they asked, were they excluded? Did not they deserve attention too? During the second year of events, additional NTID faculty and staff began to request access to these sessions - hearing men and women faculty, DHH men faculty, faculty of color, and DHH women staff members. They argued that they too experienced marginalization due to issues of gender, race, ethnicity and hearing loss, and that limiting the sessions to DHH women faculty created a divide among employees, and denied many the opportunity to benefit from the program. The complexities of the issue were

\footnotetext{
${ }^{2}$ It is important to note that although we recognized a variety of identities within this project, to our knowledge, we did not face pushback on the basis of transgender identities. That notwithstanding, in light of current debates on public restrooms and similar social policies policing gender identity, transgender identities are an important consideration.
}

(C) 2019 by Author/s 
apparent to the DHH Women social science research team. The primary goal of the team was to improve the inclusion of women in academia, and DHH women faculty were the main focus of the work to date. Yet there was also recognition that the exclusivity of the DHH Women's Connectivity Series did create a small tension, and that by limiting participation, some members of our community felt marginalized by our program.

What emerged was a powerful story of inequities and challenges amongst a host of positives: none of these DHH women were the 'only' DHH faculty member and all had ample access to visually-based communication within their work environment. All faculty at NTID are expected to communicate effectively across a variety of work-related contexts and differences in DHH communication preferences, such as signing vs. relying on voiced speech production and lipreading. There is an expectation that in public spaces (hallways, dining commons, etc.) all individuals sign their conversations so that DHH individuals are not left out of incidental conversational information. However, these practices do not eliminate barriers that DHH women faculty face. The central question we address in this paper is thus: how do DHH female academics successfully negotiate their careers given the impact of intersectional minority identities (disability, gender, etc.)? Using a case-study approach, we share the story of what these DHH women experienced, and how they decided to resolve the pushback they received when designing and implementing career development and networking opportunities for themselves.

The Connectivity Series. In 2012 and 2013, the DHH women Social Science Research team designed, conducted and analyzed two focus group interviews with DHH women faculty to examine the question of how these DHH female academics successfully negotiated their attempts to build networking and professional development for their own specific needs as DHH female faculty. Questions focused on the the impact of intersectional minority identities (disability, gender, etc.). The goal was to document individual and contextual factors that helped or hindered these women's ability to access and succeed in their career professional development, mentoring, and networking. Main topics covered included descriptions of career their career pathway including barriers and strategies to overcome barriers (see Marchetti, Foster, Schley, \& Kavin, in preparation), the influence of both formal and informal mentoring/support, and the importance of opportunities for peer networking. From this reflection on their work environment, the DHH women faculty team saw the need for resources that could give these women the same opportunities as other faculty, and they decided to develop the DHH Women's Connectivity Series. Three DHH female-identified women lead the effort - inviting speakers, scheduling, and managing their budget for these events. All three were from the same race/ethnicity category: white people. Table 1 summarizes demograhic characteristics of focus group attendees.

Table 1. Demographics of 13 Focus Group Participants

\begin{tabular}{|c|c|c|}
\hline Background & Groups & $\begin{array}{c}\text { Participants } \\
(n=13)\end{array}$ \\
\hline \multirow{4}{*}{ Highest Degree Attained } & EdD & 2 \\
\hline & $\mathrm{PhD}$ & 1 \\
\hline & M.S. & 8 \\
\hline & M.A. & 2 \\
\hline \multirow{2}{*}{ Discipline Area of Highest Degree } & STEM/SBS & 7 \\
\hline & Non-STEM/non-SBS & 6 \\
\hline \multirow{7}{*}{ Tenure and Rank } & Pre-Tenure or Tenured & 6 \\
\hline & Assistant & 4 \\
\hline & Associate & 2 \\
\hline & Non-Tenure Track & 7 \\
\hline & Lecturer & 4 \\
\hline & Senior Lecturer & 2 \\
\hline & Research Assistant Professor & 1 \\
\hline Years Worked at Univertity- $Z$ & Range & $1.5-35$ \\
\hline
\end{tabular}

From the fall of 2013 to the spring of 2017, the DHH Women's Connectivity Series hosted 21 events. Attendance ranged from a low of 2-7 people per event, to a high of 16-18 people per event, with an average of 9 attendees at each event. A number of events were targeted professional development sessions, such as "getting your feet wet with grant writing," and others added a level of networking and mentoring from other successful DHH women academics, such as "Swimming Against the Tide as a Deaf Woman Professor," and "Navigating Our Roles as Female Deaf Faculty." Table 2 summarizes dates, topics and speakers, and invited audiences for all of the DHH Women's Connectivity events between the fall of 2013 and the spring of 2017. 
9/19/13 Working Together and Moving Forward: A new Series - workshop planning

11/21/13 N Forand, D Lange, S Schley - How to Get Your Feet Wet with Grant Writing

12/5/13 Caroline Soloman, Swimming Against the Tide in Academia as a Deaf Woman Professor

$2 / 20 / 14$ Karey Pine - Getting beyond the barriers - Advice and Strategies for Success in the Academy

3/20/14 Karey Pine - Getting beyond the barriers - Advice and Strategies for Success in the Academy Part 2

4/17/14 Liisa Kauppenin, High =-Level Negotiating and Resolution Building Skills for DHH Women Faculty in STEM/SBS Fields

9/12/14 Welcome Back and Series Kick-Off

10/17/14 Dr. Khadijat Rashid, Professor, Dept of Business, Gallaudet - Finding Leadership * Opportunities in Academia

11/21/14 Dr. Carol Padden, Professor of Communication and Interim Vice Chancellor of Equity, * Diversity and Inclusion at UCSD. Breaking the Glass Ceiling: Deaf Women in Academia

2/20/15 Dr. Wendy Harbour, Association for Higher Education and Disabilities. Issues of Equity * and Diversity for Deaf and Hard of Hearing Faculty

4/3/15 Dr. G. Buckley, Interview and Discussion with NTID President $*$

9/24/15 Dr. C Marchetti, Associate Professor, RIT. A conversation about different strategies to ignite * cross-campus collaboration. DHH women faculty

10/8/15 Dr. C Marchetti, Associate Professor, RIT. A conversation about different strategies to ignite cross-campus collaboration.

10/8/15 Dr. C Marchetti, Associate Professor, RIT. A conversation about different strategies to ignite cross-campus collaboration.

10/15/15 Dr. Wendy Harbour. Assoc Exec. Director of Programs and Development at the Association on Higher Education and Disability. Navigating Our Roles as Female Deaf Faculty.

2/5/16 Dr. Kathryn Woodcock, Associate Professor, Ryerson University Toronto. Best Practices for Collaboration with External Organizations.

3/15/16 Trudy Suggs, T.S.Writing Services. Crafting the Perfect Proposal: Grant

3/16/17 Trudy Suggs, T.S.Writing Services. Saying it Right: How to Get Ahead. Writing

2/27/17 Dr. Nancy Hlibok Amann, Superintendent of CA School for the Deaf in Riverside. Casual Meet and Greet over Dinner.

2/28/17 Dr. Nancy Hlibok Amann, Superintendent of CA School for the Deaf in Riverside. The Past, * Present, and Future of Deaf Education, DHH Women Faculty.

2/28/17 Dr. Nancy Hlibok Amann, Superintendent of CA School for the Deaf in Riverside. The Past, Present, and Future of Deaf Education, All NTID Faculty

In total, eleven events were held for DHH female faculty and staff over a three-year period. Five of the events had additional open sessions for all faculty and staff. Topics included discussions with hearing and DHH guests regarding barriers to advancement and strategies for achieving career goals, a panel of experts discussing how to develop proposals for external funding, a meeting with the college Dean, and advice regarding building international networks and partnerships. Sessions took a range of formats, including on-campus and videoconference events.

Across the eleven events, $42 \mathrm{DHH}$ female faculty and staff, plus the two coordinators, attended at least one event. About two-thirds of those participants attended a single event; about 14\% attended two events, and 19\% attended three or more events (including one person who attended eight). Eight male faculty and staff attended the open events, plus an additional five hearing females.

DHH co-authors Beiter, Dannels, and Ross were all engaged in developing and implementing the Connectivity series. In 2016, these women discussed their experiences and challeges regarding DHH men and other faculty who wanted access to these events. As hearing members of the research team, coauthors Foster, Schley and Blizzard had several meetings with these DHH female faculty to support their efforts. Notes from those meetings, and narrative accounts of the DHH women's refections on what happened and the decisions that were made, were used in framing this paper. These narrative accounts were collected via requests in person and via email for written or verbal accounts of what happened. In-person accounts (via signing and/or speaking) were summarized in 
written English, and emailed back to the DHH team members, where individuals each confirmed that the narrative summaries accurately reflected their experiences and reflections. A collaborative process was used to weave together the series of events and these women's story about designing and implementing this series. First, the sequence of events was summarized narratively, using a document review of the Connectivity Series events (see Table 2), and details from the DHH female faculty's reflections.

\section{POWER-PUSH AND PUSHBACK}

In the following section we outline some of the power push and personal pushback from individuals at NTID and RIT, who despite having multiple markers of difference, or living in multiply compounding levels of jeopardy, were not initially invited to participate in the DHH Women's Connectivity Series. As illustrated below, the anxiety sensed by many already marginalized individuals who felt they were facing further marginalization was palpable. Their stories highlight two important factors within our analysis: first, whether one 'lives' in the epicenter of power or not, the feeling of losing power can prove highly threatening; and second, the similarities within the experiences of a variety of differences may in fact be a useful force to unite disempowered Others to bind together in a push for change and visibility.

The coordinators of the DHH Women's Connectivity Series shared the story of what happened:

Initially, several men DHH faculty showed up to the events, but left when they realized the events were limited to DHH women faculty. Then, several women staff asked if they could attend, and were included in the events. 'For a few deaf women staff [members], I welcomed them when they asked...often they are the ones who are teaching or have taught one course or have ambitions to become faculty in the near future.' A hearing woman from another college of RIT knew the deaf guest speaker very well, so I had to let her in the web conference... She's a good friend of the speaker and hadn't seen her in a long time... She was respectful to everyone throughout the session... I had no idea if she's hearing or deaf as I met her for the first time in the video conference room while the speaker was on the big screen. One women hearing faculty of color came to the kick-off session and I explained that the event was for DHH women only and asked [team leader] to meet with her individually. The same individual later asked me via email if she could attend a web seminar presentation by a Deaf faculty of color from another university. She challenged me by asking something like "How many deaf women of color faculty are out there that I can listen to?" I let her attend because she hopes to collaborate with Deaf persons of color on scholarship.

This pushback presented a challenge to the DHH Women social science research team. Team members had a number of reactions, with the following quotes:

I guess I felt kind of put on the spot, wanting to invite them but at the same time wanting to maintain the confidentiality and integrity of the group discussion. My first response would be 'I'll get back to you after talking with the organizers.'

Maybe slightly intrusive, but overall, I don't mind...

I had to mention what the flyer said to the person and see what his/her reaction was, then explain the situation depending on their reaction... Once in a while, some women/men apologized for not reading the flyer carefully... they were respectful and left the session. More of of a case-by-case basis...

I was pleased that the events were popular but concerned that the benefits of the separate series for DHH women would be compromised if the sessions were open to all - our presenters tailored their sessions specifically to the needs of this group.

Oy... another case of the privileged wanting access to things designed for the underprivileged.

Sociologically it makes sense. They see others receiving privileges and want the same treatment. What they fail to see is that they are not on a level playing field.

Discussing issues such as successful strategies to manage and respond to these concerns might cause conflict if both men and women were in attendance - e.g. strategies for women respond to microagressions from men on campus, or strategies to frame promotion documentation to head off potential gender bias in the promotion process. With both men and women in attendance, female participants may not feel comfortable discussing these challenges, or strategies to manage the challenges. 
However, there were men that wanted to participate because they also wanted access to the expertise and training to combat some of these challenging issues - as well as access to the very few Deaf academics invited to lead events. The men did not care if the speakers were female or male, only that they were Deaf and successful in academia; these networking opportunities were not to be missed. As the coordinators discussed this issue with the administration, all in attendance were supportive and understood why male faculty and staff wanted access, but recognized the need to protect the safe space for female faculty and staff.

Eventually, a decision was made resolve this challenge as follows. First, the DHH Women's Connectivity Series was maintained in its current format, for DHH women faculty only, to maintain a safe space for DHH female faculty to discuss any gender-biased concerns. As a result, they decided to proceed with a separate, second session open to all faculty and staff, with financial support from the Dean and President of NTID, to fund access to events for the male faculty and staff who had felt excluded and to provide a separate event for female faculty and staff only. The two separate events solved all objections. The male faculty and staff, who had initially complained about being excluded attended these sessions, expressed their appreciation to the coordinators.

There was no further pusbback after this resolution. However, implementation of this strategy impacted the DHH Women's Connectivity Series in its third year. Arranging event times was difficult, due to challenging teaching schedules of research team members. The usual day and time was changed, and fewer DHH women faculty attended. Overall, attendance at the DHH Women's Connectivity Series events was smaller; groups averaged between 6-8 women at the DHH Women only sessions, compared to 10-12 before this change. This could be because $\mathrm{DHH}$ women faculty now had a choice of going to the DHH women faculty sessions or the open sessions, or because of scheduling conflicts. Two open sessions had the same attendance as the closed sessions; one open session had higher attendance than the closed session. Nevertheless the drop in attendance by the primary population in question merits further examination. It is also possible that the $\mathrm{DHH}$ women who attended the first group of workshops received either real or perceived hostility from those who were excluded from earlier workshops, leading them to attend the more "open" workshops in subsequent semesters.

\section{DISCUSSION}

Here we examine the manifestation of these pusbbacks, and theorize why it happened and what it tells us about power within differing categories of Otherness. We also explore the ways in which further activities aimed at bringing equity and understanding to a specific marginalized group may be used to assist many types of Others (disabilities, races, gender identities, etc.) in achieving and gaining power at their institutes.

Around college campuses, physical spaces are being designated to foster dialogue. Sometimes labeled safe spaces, safe zones, or other explicitly sanctioned 'safe' areas it is hoped that in these locales at least two things may occur: those in positions of power can safely learn about Others and themselves, and Others can safely share stories and create (survival) narratives. But why are these spaces necessary? Should not all spaces be safe?

Safety has physical, intellectual, and emotional components. Physical safety, and the risk of not being physically safe, is relatively easy to define and accept. Few would openly admit wanting to show physical hostility toward another. To physically harm someone due to their otherness or to difference from the perceived norm established in the epicenter of power is often termed a hate crime, and understood by most as unacceptable behavior.

However, intellectual and emotional safety are often less obvious. Aggression to undermine this type of safety is described by flexible terms such as hostile or chilly environments/climates (note the rhetorical differences in nomenclature). At what point does an environment become chilly? And, when does it become hostile? Which is worse and can they happen at the same time? Within complex lives and contexts where multiple identities and multiculturalism evolve, we are unlikely to find answers to these questions.

While Foucault leads theorists through examinations of power and expression, feminist philosopher of science Sandra Harding (e.g., 1986, 1991, 2004) offers nuanced analyses of women in science. She explains the concept of fractured identities, where viewing individuals solely through a minority category lens is problematic, even in discourses of equity (see also Haraway, 1991). The colloquial phrase she wears multiple hats is commonly understood as one hat at a time. Harding demonstrated that in fact she is always wearing multiple hats (c.f. Derrida, 1976). Thus a woman is not just a woman, she is a multiplicity. She is race, religion, gender, ethnicity, and so on, a collage of intersectionality. While one identity may surface more than another, they are all always in play and within a kaleidoscope of lived experience. One does not have a single identity then, with an ever-smaller slice of the pie as additional hyphenated-terms are added to one's identity description; rather, everyone has multiple fractured identities - with specific features emerging more strongly at times in contrast to others.

When considering the similarities and differences that separate and unite DHH women faculty, the concept of fractured identities is useful. DHH women faculty have multiple identity hats which they are always wearing. While gender and race are likely the two most studied markers of difference in STEM career attainment (e.g., Harding, 1991; Hubbard, 1990; Wyer et al., 2014) other difference signifiers also exist, and depending upon the context may 
be as powerful as race and gender within the hierarchical, concentric circles of power. Such signifiers may include religion, sexuality, and (dis)ability. Thus, at an academic institution that houses NTID, DHH and hearing identity (aka, audiological (dis)ability) may be a very important signifier for potential personal and professional success. Our population of women who were also DHH consisted of a compelling group of twice marginalized academics living and working in double jeopardy, with fractured identities, who encountered power pushes with and pushback from individuals with unrecognized privilege.

However, this story begs the question of the ethics of separate spaces. What does it mean for one group (say, DHH women) to have a separate space, so that information, opportunities, and resources are withheld from other also-marginalized groups? Multiple groups have multiple overlapping and separate needs re. succeeding in a workplace where they are not the majority. By definition, having a separate space leaves others out. We have no answer, but the "What about me?" question becomes particularly poignant from an intersectional lens.

\section{CONCLUSION}

In the 1980s, Harding (see 2004, 1991) made the claim that to change the beneficiaries and practitioners of science and technology would take more than structural change and political posturing; it would need cultural change. At this juncture, her claim was that 'add women and stir' was not enough. If women, with multiple standpoints and fractured identities (e.g. being women and DHH), are to have a fair chance at excelling in the STEM disciplines, we need to change how we think about what we know, and how we define STEM, who can practice it, and what is and is not acceptable. It is not enough to only make room for Others in STEM, it must also include the value of Otherness into the very content and context of STEM (see also Longino, 1990).

While some argue that the 'issues' facing women in STEM may be resolved through better mentoring, other critical scholars ask how mentoring can help if the mentor is an unknowing participant in the mainstream culture of STEM and captive to stagnant culture? Structural and political changes in policy and/or law will only go so far; the context of STEM includes a variety of cultural differences inhabited by multiple Others, all unique in their cultural differences expressed through fractured identities. To change STEM is to change the cultural context, and to change the culture is to understand the current cultural contexts of those within it, especially those who inhabit the margins (i.e., Others). Therefore, what we learn from women who are also DHH assists us in learning how the culture might change, and in (re)thinking how other Others (e.g., women and men with other differences, other disabilities, other identities) might also benefit from a better understanding of this group. To illustrate, what are the similarities between a woman, white, Deaf, mathematician and a man, black, hearing, chemist? And, how can we identify shared similarities within their differences to create better contexts that incorporate and commend STEM exploration, and take advantage of nuanced cultural difference, rather than view it as threatening to the epicenter of power?

Such cultural change of the level and depth that we imagine above will take work and time. The academy and its inhabitants (both faculty and administrators) need to make efforts to better understand who we are - as opposed to what we are not - to create a world in which STEM is accessible. Through such accessibility, a more robust arena for intellectual development may well occur.

It is generally argued that we do not see women in STEM fields because of gender differences in scientific ability; gender differences arising from social selection, based on gender discrimination as well as gender difference in role performance and the allocation of resources and rewards; gender differences arising from self-selection, including marriage and motherhood and their consequences, as well as gender differences in career commitment; and outcomes of accumulation of advantage and disadvantage, including the 'Matthew effect' (see Zuckerman, 2001, p. 69). The women in this study all achieved high-level academic careers at a large university focused on career and technical education. By continuing the DHH Women's Connectivity Series for DHH women and adding a second session open to the community, this group of DHH women modeled inclusivity while honoring their own needs of mentoring and career support. Addressing one group's needs for a separate space can be accomplished while also providing access to these events for the wider community. This is a model example of effective powerpush. DHH women on this project focused on improving their social and cultural positioning within an inequal culturally-mediated power distribution. They received pushback from the larger community, and found one way to address the larger community's needs as well as their own. While we cannot answer whether multiple facets of the "What about me?" question were resolved, these women found a solution.

Robinson and Henner (2018) contend that universities that teach American Sign Language (as a "foreign language;" in an interpreting program; as part of a Deaf Studies program) profit from these courses. In return, these institutions have an obligation to make sure that disabled students and disabled academics are able to succeed in academia. They essentially argue that disabled students, communities and academics have an opportunity to push back here, capitalizing on the popularity of ASL to expand accessible institutions and resources, and in effect, ensuring that disabled people have a solid place within higher education. In effect, the DHH women in this story 
pushed back to maintain their own space, while allowing for the needs of others having access to these opportunities too. Arguably, it is not "their" job to additionally shoulder the responsibility of getting the same support and resources for other non-majority groups, and perhaps the other groups did not gain access to the same levels of support and resources that they deserve. Their story provides an opportuntity to contribute to literature on diversity in higher education - literature which often excludes not only disability issues, but also Deaf issues, attending more narrowly to race, class and gender. While the DHH authors of this paper firmly held on to the locus of themselves in the "What about me?" question, there are undoubtedly other intersectional loci which remain uncentered.

\section{ACKNOWLEDGEMENTS}

The DHH Women Faculty Team who conducted the research interviews and implemented the DHH Women's Connectivity Series consisted of Annemarie Ross, Wendy Dannels, Karen Beiter, Denise Kavin, and Susan Foster.

This material is based upon work supported by the ADVANCE RIT grant which is funded through the National Science Foundation under Award No. HRD-1209115. Any opinions, findings, and conclusions or recommendations expressed in this material are those of the author(s) and do not necessarily reflect the views of the National Science Foundation.

Disclosure statement: No financial interest or benefit has arisen from applications of this project.

Data availability statement: Data is confidential and not available to share. They are located on a secure server housed within RIT's ADVANCE Project office.

\section{REFERENCES}

Barbercheck, M. (2009). Science, Sex, \& Stereotypical Images in Scientific Advertising. Chapter 10. Wyer., M., Barbercheck, M., Giesman, D. Ozturk, H., \& Wayne, M. (Eds.), Women, Science, and Technology: A Reader in Feminist Science Studies, 2nd Ed., New York, NY: Routledge, 118-132.

Bialka, C. S. and Morro, D. (2017). "What's Disability Got to Do With It?" Examining Ability Privilege in a Disability Studies Course. Journal of College and Character, 18(1), 28-45. https://doi.org/10.1080/2194587X.2016.1260478

Blizzard, D. (2007). Looking Within: A Sociocultural Examination of Fetoscopy (Basic Bioethics) (1 ed.). Cambridge, MA: The MIT Press. https://doi.org/10.7551/mitpress/7383.001.0001

Brown, N. and Leigh, J. (2018) Ableism in academia: where are the disabled and ill academics?, Disability \& Society, 33:6, 985-989. https://doi.org/10.1080/09687599.2018.1455627

Burch, S. and Kafer, A. (2010). Deaf and disability studies: Interdisciplinary perspectives. Gallaudet University Press.

Cheng, C. (2008). Marginalized masculinities and hegemonic masculinity: An introduction. The Journal of Men's Studies, 7(3), 295-315. https://doi.org/10.3149/jms.0703.295

Clancy, K. B., Lee, K., Rodgers, E. M. and Richey, C. (2017). Double jeopardy in astronomy and planetary science: Women of color face greater risks of gendered and racial harassment. Journal of Geophysical Research: Planets, 122(7), 1610-1623. https://doi.org/10.1002/2017JE005256

Clarke, E. H. (1873). Sex in Education: or; A Fair Chance for the Girls. Boston, MA: J. R. Osgood and Co.

Coston, B. M. and Kimmel, M. (2012). Seeing privilege where it isn't: Marginalized masculinities and the intersectionality of privilege. Journal of Social Issues, 68(1), 97-111. https://doi.org/10.1111/j.15404560.2011.01738.x

Crenshaw, K. (1989). Demarginalizing the Intersection of Race and Sex: A Black Feminist Critique of Antidiscrimination Doctrine, Feminist Theory and Antiracist Politics. University of Chicago Legal Forum, 1989(1), 139-167.

D’souza N. (2004) Is Universal Design a Critical Theory?. In: Keates S., Clarkson J., Langdon P., Robinson P. (eds) Designing a More Inclusive World. Springer, London

Dench, G. (2006). The rise and rise of meritocracy. Oxford, UK; Malden, MA: Blackwell Publishing in association with The Political Quarterly.

Derrida, J. (1976). Of Grammatology. 1967. Trans. Gayatri Chakravorty Spivak. Baltimore: Johns Hopkins University Press, 247-72.

Dolmage, J. T. Academic Ableism (Corporealities: Discourses Of Disability). University of Michigan Press. Kindle Edition.

Drago, R., Colbeck, C., Stauffer, K., Pirretti, A., Burkum, K., Fazioli, J., Lazarro, G. and Habasevich, T. (2005). Bias against Caregiving. Academe, 91(5), 22-25. https:// doi.org/10.2307/40252829 
El-Alayli, A., Hansen-Brown, A. A. and Ceynar, M. (2018). Sex Roles, 79, 136. https://doi.org/10.1007/s11199017-0872-6

Evans, N. J., Broido, E. M., Brown, K. R., Wilke, A. K. and Herriott, T. K. (2017). Faculty and Staff with Disabilities (Chapter 7). In Disability in higher education: A social justice approach. p. 197-222. Available at: https://ebookcentral.proquest.com

Finkelstein, M. J., Conley, V. M. and Schuster, J. H. (2016). The faculty factor: Reassessing the american academy in a turbulent era. Baltimore, Maryland: Johns Hopkins University Press.

Foucault, M. (1979). Discipline and Punish: The Birth of the Prison. New York, NY: Vintage Books.

Fox Keller, E. F. (1995). Reflections on Gender and Science. New Haven, CT: Yale University Press.

Garland-Thomson, R. (2017). Integrating Disability, Transforming Feminist Theory. In L. J. Davis (Ed.), The Disability Studies Reader (5th ed., pp. 360-380). New York, NY: Routledge.

Grosjean, F. (2001). The right of the deaf child to grow up bilingual. Sign Language Studies, 1(2), 110-114. https://doi.org/10.1353/sls.2001.0003

Guarino, C. M. and Borden, V. M. H. (2017). Faculty Service Loads and Gender: Are Women Taking Care of the Academic Family? Research in Higher Education, 58(6), 672-694. https:/ / doi.org/10.1007/s11162-017-9454-2

Haraway, D. J. (1991). Simians, cyborgs, and women: the reinvention of nature. New York: Routledge.

Harding, S. G. (1986). Other 'Others' and Fractured Identities: Issues for Epistemologists, Chapt. 7 in The Science Question in Feminism. Ithaca, NY: Cornell University Press.

Harding, S. G. (1991). Whose Science? Whose Knowledge? Thinking from Women's Lives. Ithaca, N.Y.: Cornell University Press.

Harding, S. G. (2004). The Feminist Standpoint Theory Reader: Intellectual and Political Controversies (1 ed.). New York, NY: Routledge

Hehir, T. (2005). New directions in special education: eliminating ableism in policy and practice. Harvard Education Press.

Hehir, T. and Katzman, L. I. (2012). Effective inclusive schools: designing successful schoolvide programs. Jossey-Bass.

Higgins, M. and Lieberman, A. (2016). Deaf Students as a Linguistic and Cultural Minority: Shifting Perspectives and Implications for Teaching and Learning. Journal of Education, 196(1), 9-18. https://doi.org/10.1177/002205741619600103

Hubbard, R. (1990). The Politics of Women's Biology. New Brunswick, NJ: Rutgers University Press.

Iantaffi, A., Morley, L. and Walsh, V. (1996). Women and disability in higher education: a literature search. Breaking Boundaries: Women in Higher Education, 180-86.

Inckle, K. (2018) Unreasonable adjustments: the additional unpaid labour of academics with disabilities. Disability \& Society, 33(8), 1372-1376. https://doi.org/10.1080/09687599.2018.1480263

Individuals with Disabilities Education Act, 1997. Available at: https://www.congress.gov/105/plaws/publ17/PLAW-105publ17.pdf

Kerschbaum, S. L., Eisenman, L. T. and Jones, J. M. (Eds.). (2017). Negotiating disability: Disclosure and higher education. University of Michigan Press. https://doi.org/10.3998/mpub.9426902

King, D. K. (2016). Multiple jeopardy, multiple consciousness: The context of a Black feminist ideology. In Race, Gender and Class (pp. 36-57). New York, NY: Routledge.

Longino, H. E. (1990). Science as Social knowledge: Values and Objectivity in Scientific Inquiry. Princeton, NJ: Princeton University Press.

Mace, R. (1985). Universal Design, Barrier free environments for everyone. Designers West, Los Angeles, CA.

MacKinnon, C. (1987). Feminism Unmodified. Harvard University Press.

Marchetti, C., Foster, S., Schley, S. and Kavin, D. Under preparation. Pathways of Deaf and Hard of Hearing Women Faculty to Careers in Higher Education. To be re-submitted to Disability Studies Quarterly.

Matthew, P. A. (Ed.). (2016). Written/unwritten: Diversity and the hidden truths of tenure. Chapel Hill: University of North Carolina Press. https://doi.org/10.5149/northcarolina/9781469627717.001.0001

McIntosh, P. and Privilege, W. (1989). Unpacking the invisible knapsack. Peace and Freedom, 49, 10-12.

Meyer, A., Rose, D. H. R. and Gordon, D. (2014). Universal Design for Learning. Available at: http://udltheorypractice.cast.org/home?3

Morgan, K. P. (1996). Describing the emperor's new clothes: Three myths of educational (in-) equity. The gender question in education: Theory, pedagogy, \& politics, 105-122. https://doi.org/10.4324/9780429496530-11

Power, D. (2005). Models of deafness: Cochlear implants in the Australian daily press. Journal of Deaf Studies and Deaf Education, 10(4), 451-459. https://doi.org/10.1093/deafed/eni042

Public Law. (1990). Americans with Disabilities Act of 1990. Public Law. 104 Stat. 328. Available at: https://www.wbdg.org/ccb/ASTAND/ada.pdf

Punch, R. (2016). Employment and adults who are deaf or hard of hearing: Current status and experiences of barriers, accommodations, and stress in the workplace. American annals of the deaf, 161(3), 384-397. https://doi.org/10.1353/aad.2016.0028 
Robinson, O. and Henner, J. (2018). Authentic Voices, Authentic Encounters: Cripping the University through American Sign Language. Disability Studies Quarterly, 38(4). https://doi.org/10.18061/dsq.v38i4.6111

Rockquemore, K. A. and Laszloffy, T. (2008). The Black academic's guide to winning tenure - without losing your soul. Boulder, CO: Lynn Rienner Publishers.

Shuttleworth R. and Meekosha H. (2017) Accommodating Critical Disability Studies in Bioarchaeology. In: Byrnes J., Muller J. (eds) Bioarchaeology of Impairment and Disability. Bioarchaeology and Social Theory. Springer, Cham. https://doi.org/10.1007/978-3-319-56949-9_2

Siegel, L. M. (2008). The human right to language: Communication access for deaf children. Washington, DC: Gallaudet University Press. https://doi.org/10.1353/hrq.2008.0010

Thomson, R. G. (2017). Extraordinary bodies: Figuring physical disability in American culture and literature. Columbia University Press.

Turner, J. D., Haddix, M. M., Gort, M. and Bauer, E. B. (2017). Humanizing the Tenure Years for Faculty of Color: Reflections from STAR Mentors. Journal of Literacy Research, 49(4), $582-589$. https://doi.org/10.1177/1086296X17733493

Turner, J. D., Walker-Dalhouse, D. and McMillon, G. T. (2005). Crossing over to Canaan: Engaging distinguished women and/or minority scholars in critical conversations about tenure. In Maloch, B., Hoffman, J., Schallert, D. L., Fairbanks, C. M. \& Worthy, J. (Eds.), 54th Yearbook of the National Reading Conference (pp. 403-15). Oak Creek, WI: National Reading Conference.

Valle, J. W. and Connor, D. J. (2011). Rethinking disability : a disability studies approach to inclusive practices. McGraw-Hill.

Weisel, A. and Cinamon, R. G. (2005). Hearing, deaf, and hard-of-hearing Israeli adolescents' evaluations of deaf men and deaf women's occupational competence. Journal of Deaf Studies and Deaf Education, 10(4), $376-389$. https://doi.org/10.1093/deafed/eni045

Williams, J. C. (2004). Hitting the Maternal Wall-Before They Reach a" Glass Ceiling” in Their Careers, Women Faculty May Hit a" Maternal Wall". Academe Bulletin of the American Association of University Professors, $90,16$. https://doi.org/10.2307/40252700

Williams, Phillips, K. W. and Hall, E. V. (2014). Double Jeopardy? Gender Bias Against Women of Color in Science. San Francisco, CA; UC Hastings College of Law/WorkLifeLaw. Available at: http:/ /www.toolsforchangeinstem.org/tools/double-jeopardy-report (Accessed 30 June 2016)

Wolbring, G. (2008). The politics of ableism. Development, 51(2), 252-258. https:/ / doi.org/10.1057/dev.2008.17

Woodcock, K., Rohan, M. J. and Campbell, L. (2007). Equitable representation of deaf people in mainstream academia: Why not?. Higher Education, 53(3), 359-379. https:/ / doi.org/10.1007/s10734-005-2428-x

Woodward, J. and Allen, T. (1993). Models of deafness compared: A sociolinguistic study of deaf \& hard of hearing teachers. Sign Language Studies, 113-126. https:/ / doi.org/10.1353/sls.1993.0014

Wyer, M., Barbercheck, M., Giesman, D., Ozturk, H. O. and Wayne, M. 2009. Women, Science, and Technology: A Reader in Feminist Science Studies (3nd ed.). New York, NY: Routledge.

Young, C. (2014). This is What I mean When I Say "White Feminism." Blog post. Available at: http:/ / battymamzelle.blogspot.com/2014/01/This-Is-What-I-Mean-When-I-Say-White-Feminism.html\#. V3Ukb5MrLMK (Accessed 30 June 2016)

Zschoche, S. (1989). Dr. Clarke Revisited: Science, True Womanhood, and Women Collegiate Education. History of Education Quarterly, 29(4), 545-569. https://doi.org/10.2307/369063

Zuckerman, H. (2001). The Careers of Men and Weomn Scientists: Gender Differences in Career Attainments. In Wyer, M., Giesman, D., Barbercheck, M., Ozturk, H. \& Wayne, M. (Eds). Women, Science and Technology: A Reader in Feminist Studies, $1^{\text {st }}$ Edition. New York, NY: Routledge. 69-78.

Zuska. (2007, July 27). Friday Bookshelf: Women, Science and Technology. [Blog post]. Available at: http:/ / thusspakezuska.scientopia.org/2007/07/27/friday-bookshelf-women-science-and-technology/

(Accessed 4 October 2017). 